\title{
Arachidonic acid pathway: A molecular target in human testicular cancer (Review)
}

\author{
MASAHIDE MATSUYAMA and RIKIO YOSHIMURA \\ Department of Urology, Osaka City University Graduate School of Medicine, \\ 1-4-3 Asahi-machi, Abeno-ku, Osaka 545-8585, Japan
}

Received September 30, 2008; Accepted March 9, 2009

DOI: $10.3892 / \mathrm{mmr} 00000131$

\begin{abstract}
Recent epidemiological studies and animal experiments have demonstrated that non-steroidal antiinflammatory drugs (NSAIDs) reduce the incidence of colorectal carcinoma. Cyclooxygenase (COX), the first oxidase in the process of prostaglandin production from arachidonic acid, is the principal target of NSAIDs. Due to its inhibition by NSAIDs, the COX enzyme may be involved in the initiation and/or promotion of carcinogenesis. Lipoxygenase (LOX) is also an enzyme active in the early stages of the pathway for producing leukotrienes from arachidonic acid, and may, like COX, be involved in the initiation and/or promotion of carcinogenesis. Peroxisome proliferator activator-receptor (PPAR) $-\gamma$ is a ligand-activated transcriptional factor belonging to the steroid receptor superfamily. PPAR- $\gamma$ plays a role in both adipocyte differentiation and carcinogenesis, and is a target for the cell growth modulation of NSAIDs. In this review, we report the expression of COX-2, LOX and PPAR- $\gamma$ in human testicular cancer tissues, as well as the effects of COX-2 and LOX inhibitors and PPAR- $\gamma$ ligands.
\end{abstract}

\section{Contents}

1. Introduction

2. Arachidonic acid pathway

3. Peroxisome proliferator activator-receptor

4. Cyclooxygenase and testicular cancer

5. Lipoxygenase and testicular cancer

6. Peroxisome proliferator activator-receptor- $\gamma$ and testicular cancer

7. Conclusion

Correspondence to: Dr Rikio Yoshimura, Department of Urology, Osaka City University Hospital, 1-4-3 Asahi-machi, Abeno-ku, Osaka 545-8585, Japan

E-mail: jasmin@med.osaka-cu.ac.jp

Key words: cyclooxygenase, lipoxygenase, peroxisome proliferator activator-receptor- $\gamma$, testicular cancer

\section{Introduction}

Testicular cancer (TC) is very rare. Over $90 \%$ of all TCs are germ cell tumors (seminoma and non-seminoma), and the remaining percentage are non-germinal tumors. The survival rate of TC has improved in recent years, reflecting the development and refinement of effective combination chemotherapy. However, it is still necessary to improve the treatment of the disease.

Non-steroidal anti-inflammatory drugs (NSAIDs) have had anti-tumor effects in TC patients and have thus attracted a great deal of attention. The typical target of NSAIDs is cyclooxygenase (COX). In recent reports, a number of patients had a significantly lowered risk of colorectal cancer with continued use of NSAIDs, typified by aspirin. Consequently, the suppression of carcinogenesis through the administration of NSAIDs has come into focus. It has also been reported that the size and number of adenomas were markedly reduced when sulindac, a type of NSAID, was administered to patients with familial adenomatous polyposis, a group at high risk for colorectal cancer (1).

It is known that NSAIDs inhibit the activity of COX and the production of prostaglandin (PG). NSAIDs also stimulate peroxisome proliferator activator-receptor (PPAR)- $\gamma$ and inhibit the production of chemical mediators, such as tumor necrosis factor- $\alpha$, interleukin- $1 \beta$ and interleukin- 6 , through the expression of PPAR $-\gamma$ in leukocytes. PPAR $-\gamma$ is thus a promising target for cell growth modulation by NSAIDs.

In this review, we discuss the possibility that the target of the arachidonic acid pathway metabolite may be a new anticancer strategy for human TC.

\section{Arachidonic acid pathway}

Metabolism of arachidonic acid by either the COX or the lipoxygenase (LOX) pathway generates eicosanoids, which have been implicated in the pathogenesis of a variety of human diseases, including cancer, and are considered to play a key role in tumor promotion, progression and metastasis (2).

COX is the first enzyme in the pathway for producing PG and thromboxane (Tx) from arachidonic acid, and can occur as three isoforms, COX-1, COX-2 and COX-3. The enzymes of both COX-1 and -2 are transformed from the cell membrane phospholipid to arachidonic acid by the phospholipase $\mathrm{A}_{2}$, and then transform arachidonic acid to $\mathrm{PGH}_{2}$ through $\mathrm{PGG}_{2}$. 
COX-1 occurs in tissues and cells and works to protect the cell. COX-2 is expressed momentarily and strongly in response to growth factors and various endotoxins. It is involved in inflammation, cell proliferation and differentiation (3). COX-2 has also been shown to play an important role in carcinogenesis (1). Although the existence of COX-3 has recently been reported, it remains controversial.

LOX is the first enzyme in the pathway that produces leukotriene (LT) from arachidonic acid. The isoenzymes of LOX include 5-LOX, 12-LOX and two 15-LOX isoforms (15-LOX-1, 15-LOX-2). These catalyze the biosynthesis of biologically active compounds such as LTs and hydroxyeicosatetraenoic acids (HETEs) (4,5). 5-LOX catalyzes the first step in the oxygenation of arachidonic acid to produce 5-hydroperoxyeicosatetraenoic acid (5-HPETE), and the subsequent metabolism of 5-HPETE to 5-HETE and LTs. LTs belong to a key group of pro-inflammatory mediators that are synthesized from arachidonic acid via the 5-LOX pathway. The activity of 5-LOX leads to the formation of unstable $\mathrm{LTA}_{4}$, which can be converted into $\mathrm{LTB}_{4}$ or cysteinyl LTs $\left(\mathrm{LTC}_{4}, \mathrm{LTD}_{4}\right.$ and $\left.\mathrm{LTE}_{4}\right)(6)$.

12-LOX, which includes platelet 12-LOX and leukocyte 12-LOX, oxygenates arachidonic acid at position C-12 to produce 12-hydroperoxyeicosatetraenoic acid followed by 12-HETE (2). Whereas 5-LOX, 12-LOX and 15-LOX-1 have pro-tumorigenic roles, $15-\mathrm{LOX}-2$ appears to have an anticarcinogenic role.

\section{Peroxisome proliferator activator-receptor}

PPARs are members of the nuclear receptor superfamily of ligand-activated transcriptional factor such as steroids, thyroid hormones, vitamin $\mathrm{D}_{3}$ and retinoic acid (7). PPAR binds to the peroxisome proliferator response element as a heterodimer with the retinoic receptor in the regulation of PPAR target genes. PPARs may be important immunomodulatory factors as well as fatty acid regulators, modulating these activities in different immune cell types such as monocyte/macrophages, lymphocytes and endothelial cells.

Three PPAR subtypes ( $\alpha, \beta$, and $\gamma$ ) have been identified. PPAR- $\alpha$ is highly expressed in the liver, heart, kidney, muscle, brown adipose tissue and gut tissues, which exhibit high carbolic rates towards fatty acid (8). PPAR- $\beta$ is expressed ubiquitously, and its function is relatively unknown (9). Recent studies suggest that PPAR- $\beta$ may be a target for NSAIDinduced tumor suppression in colorectal tumors. PPAR- $\gamma$ is expressed at high levels in adipose tissue and is a critical regular of adipocyte differentiation. In addition, PPAR- $\alpha$ and $-\gamma$ may be important immunomodulatory factors. PPAR- $\alpha-$ knockout mice exhibit exacerbated inflammatory responses, and $\mathrm{LTB}_{4}$, a chemotactic mediator, seems to regulate its own clearance as an agonist of PPAR- $\alpha$. PPAR $-\gamma$ is also expressed in the immune system tissues and cells (spleen, bone marrow, monocytes, helper T-cell clones) and skeletal tissues (bone, synovium, chondrocytes) (8).

Data have shown that PPAR- $\gamma$ ligands lead to the inhibition of phorbol ester-induced nitric oxide and macrophagederived cytokines. PPAR- $\gamma$ ligands also induce apoptosis in macrophage, fibroblast and endothelial cells (10). PPAR- $\gamma$ plays a role in both adipocyte differentiation and carcino-
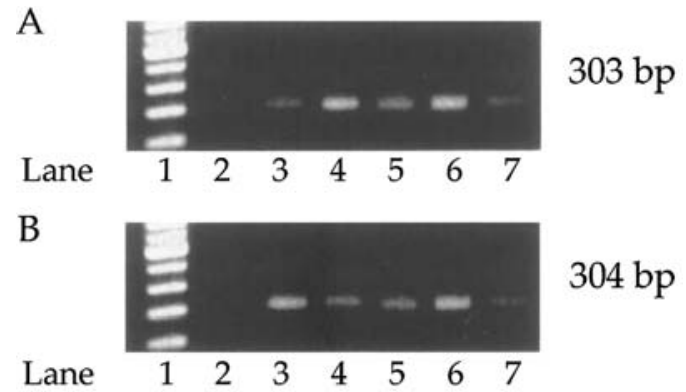

$304 \mathrm{bp}$

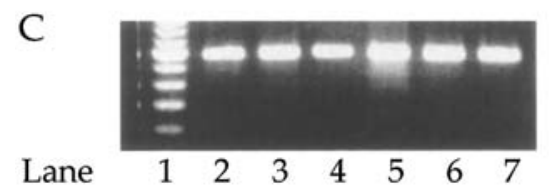

$598 \mathrm{bp}$

Figure 1. RT-PCR analysis of COX-1 and COX-2 in TC and NT tissues. Total RNA was purified from 10 TC samples (2 seminoma, 2 embryonal carcinoma, 2 yolk sac tumors, 2 choriocarcinoma, 2 teratoma). (A) COX-1, (B) COX-2, (C) G3PDH. Lane 1, markers; 2, normal testis; 3, seminoma; 4, embryonal carcinoma; 5 , yolk sac tumor; 6 , choriocarcinoma; 7 , teratoma.

genesis. Its ligands lead to the inhibition of nitric oxide, cytokine, chemokine and adhesion molecule expression, in part by antagonizing the activities of transcriptional factors. Furthermore, PPAR- $\gamma$ ligands, including anti-diabetic thiazolidinedione (such as troglitazone) and 15-deoxy- $\Delta^{12,14}$ prostaglandin $\mathrm{J}_{2}\left(15-\mathrm{d}-\mathrm{PGJ}_{2}\right)$, have potent tumor modulatory effects on several types of tumors $(11,12)$.

\section{Cyclooxygenase and testicular cancer}

In a previous study, we used immunohistochemical staining and RT-PCR to determine that COX-1 and -2 expression was stronger in all types of TC (seminoma, embryonal carcinoma, yolk sac tumor, choriocarcinoma and teratoma) than in normal testis (NT) tissue (72 TC and 20 NT tissues) (Fig. 1). We classified 2 categories (epithelium and blood vessel) in TC and NT tissues and examined the intensity of COX-1 and -2 expression in the samples. There were no significant differences in the intensity of COX-1 and -2 expression between any of the types of TC and NT tissues (13).

However, we reported COX-2 expression to be more intensive and extensive in urological cancer tissue (kidney, bladder and prostate) than in normal urological tissues. Nevertheless, there were no significant differences in the intensity of COX-1 expression between urological cancer and normal urological tissues (14-16). The cause may have been associated with the amount of PG, which was increased in the TC, evidenced by the fact that PG quantity was increased in the breast cancer tissue compared to neighboring normal breast tissue and that the expression of both COX-1 and -2 was increased (17).

In this experiment, significant induction of apoptosis was not achieved by the administration of seven types of COX-2 inhibitors $(10-80 \mu \mathrm{M})$ into the human TC cell line NEC-8 (Table I). Additionally, we did not demonstrate the significance of any of the selective COX-2 inhibitors (meloxicam, nimesulide and NS398) or the relatively poor selective COX-2 inhibitors (ibuprofen, indomethacin, piroxicam and s-naproxen). To date, no further data on TC and COX-2 have been reported. 

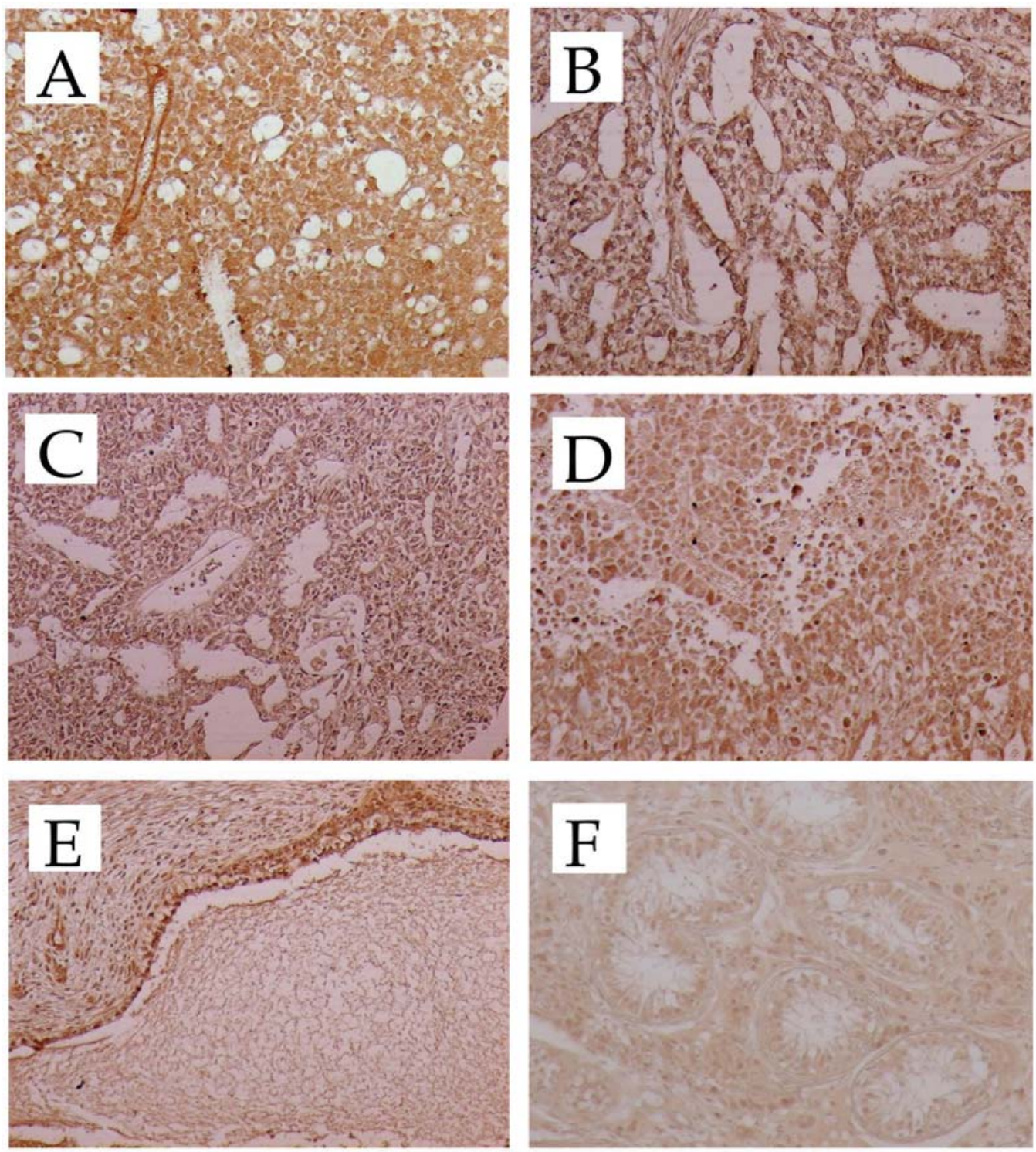

Figure 2. 5-LOX immunostaining in TC and NT tissues. We detected significantly strong 5-LOX expression in all types of TC tissue: (A) seminoma, (B) embryonal carcinoma, (C) yolk sac tumors, (D) choriocarcinoma and (E) teratoma, whereas 5-LOX expression was very weak in NT tissues (F).

In conclusion, though COX-2 expression is strong in TC, the anti-cancer effect of COX-2 inhibitor is very weak in TC patients with a single administration at a clinical dose. The COX-2 inhibitor is suitable for chemopreventive therapy.

\section{Lipoxygenase and testicular cancer}

Using immunohistochemical staining, we demonstrated that 5- and 12-LOX expression is stronger, more intense and extensive, in all types of TC compared to NT tissue (Fig. 2). There were no significant differences in the intensity of 5-and 12-LOX expression among all types of TC and NT tissues (18).

Using the MTT assay, some but not all LOX inhibitors at $10-80 \mu \mathrm{M}$ were shown to reduce the viability of NEC-8 (Table I). The 5-LOX inhibitor appeared more potent than the 12-LOX inhibitor (18). TC cells treated with some LOX inhibitor $(50 \mu \mathrm{M})$ showed chromatin condensation, cellular shrinkage, apoptotic bodies and cytoplasmic condensation by Hoechst staining. TC cells treated with 5-LOX inhibitor
$(100 \mu \mathrm{M})$ also entered early apoptosis, but did not undergo late apoptosis, necrosis or DNA fragmentation by flow cytometry. Goto et al reported that 5-LOX at least plays an important role in the growth of estrogen-responsive cells, and that $\mathrm{LTD}_{4}$ induces the apoptosis of these cells (19).

In conclusion, 5-LOX expression is strong in TC. The anti-cancer effect of the 5-LOX inhibitor is significantly stronger than the effects of the COX-2 inhibitor, but is weak in TC patients with a single administration at a clinical dose. The 5-LOX inhibitor, like the COX-2 inhibitor, is suitable for use in chemopreventative therapy.

\section{Peroxisome proliferator activator-receptor $-\gamma$ and testicular cancer}

As shown by immunohistochemical staining and RT-PCR, PPAR- $\gamma$ expression was increased in all types of TC tissues as compared with NT tissues. There were no significant differences among 5 histopathologic groups. We classified 2 categories (epithelium and blood vessel) in TC and NT tissues, 
Table I. Effects of COX and LOX inhibitors, and the PPAR- $\gamma$ ligand in the viabity of the human TC cell line NEC-8.

\begin{tabular}{|c|c|c|c|c|c|}
\hline & $5 \mu \mathrm{M}$ & $10 \mu \mathrm{M}$ & $20 \mu \mathrm{M}$ & $40 \mu \mathrm{M}$ & $80 \mu \mathrm{M}$ \\
\hline \multicolumn{6}{|l|}{ COX-2 inhibitors } \\
\hline \multicolumn{6}{|l|}{ Selective COX-2 inhibitors } \\
\hline Meloxicam & Not shown & $118.3 \%$ & $105.4 \%$ & $101.4 \%$ & $89.7 \%$ \\
\hline Nimesulide & Not shown & $111.2 \%$ & $107.4 \%$ & $104.0 \%$ & $105.3 \%$ \\
\hline NS398 & Not shown & $113.2 \%$ & $108.3 \%$ & $94.3 \%$ & $80.2 \%$ \\
\hline \multicolumn{6}{|l|}{ Poor selective COX-2 inhibitors } \\
\hline Ibuprofen & Not shown & $109.1 \%$ & $118.8 \%$ & $115.1 \%$ & $103.5 \%$ \\
\hline Indomethacin & Not shown & $102.3 \%$ & $104.5 \%$ & $98.9 \%$ & $87.8 \%$ \\
\hline Piroxicam & Not shown & $105.4 \%$ & $113.2 \%$ & $94.3 \%$ & $79.2 \%$ \\
\hline S-naproxen & Not shown & $117.1 \%$ & $98.8 \%$ & $104.5 \%$ & $94.5 \%$ \\
\hline \multicolumn{6}{|l|}{ LOX inhibitors } \\
\hline 5-LOX inhibitor (caffeic acid) & Not shown & $98.7 \%$ & $96.3 \%$ & $72.8 \%$ & $54.4 \%$ \\
\hline 12-LOX inhibitor (baicalein) & Not shown & $102.1 \%$ & $98.1 \%$ & $96.6 \%$ & $62.8 \%$ \\
\hline Non-selective LOX inhibitor (NDGA) & Not shown & $97.1 \%$ & $82.4 \%$ & $50.3 \%$ & $43.2 \%$ \\
\hline \multicolumn{6}{|l|}{ PPAR $-\gamma$ ligands } \\
\hline Troglitazone & $51.4 \%$ & $38.4 \%$ & $36.7 \%$ & $37.9 \%$ & Not shown \\
\hline $15-\mathrm{d}-\mathrm{PGJ} \mathrm{J}_{2}$ & $76.2 \%$ & $68.4 \%$ & $55.7 \%$ & $51.6 \%$ & Not shown \\
\hline
\end{tabular}

The dose-response analysis of viability in the human TC cell line NEC- 8 treated with COX-2 and LOX inhibitors and PPAR- $\gamma$ ligands (5-80 $\mu \mathrm{M}$, $48 \mathrm{~h}$ ) was measured by the MTT assay and expressed as a \% of control culture conditions.

Table II. Statistical analysis of PPAR- $\alpha,-\beta$, and $-\gamma$ immunostaining.

\begin{tabular}{llcc}
\hline $\begin{array}{l}\text { Immuno- } \\
\text { staining }\end{array}$ & \multicolumn{1}{c}{ Tumor type } & $\begin{array}{c}\text { Epithelium } \\
(\text { mean } \pm \text { SD })\end{array}$ & $\begin{array}{c}\text { Blood vessel } \\
(\text { mean } \pm \text { SD) }\end{array}$ \\
\hline PPAR- $\alpha$ & Seminoma & $2.2 \pm 0.8$ & $1.7 \pm 0.9$ \\
& Embryonal carcinoma & $2.4 \pm 1.1$ & $2.1 \pm 1.0$ \\
& Yolk sac tumor & $1.8 \pm 1.0$ & $1.6 \pm 0.7$ \\
& Choriocarcinoma & $2.5 \pm 1.2$ & $2.0 \pm 0.9$ \\
& Teratoma & $1.8 \pm 0.9$ & $1.6 \pm 0.9$ \\
& Normal testis & $2.5 \pm 1.1$ & $2.1 \pm 0.9$ \\
PPAR- $\beta$ & Seminoma & $2.4 \pm 0.9$ & $2.2 \pm 1.1$ \\
& Embryonal carcinoma & $2.6 \pm 1.4$ & $2.3 \pm 1.2$ \\
& Yolk sac tumor & $2.5 \pm 1.4$ & $2.1 \pm 0.6$ \\
& Choriocarcinoma & $2.2 \pm 1.0$ & $1.9 \pm 0.9$ \\
& Teratoma & $2.4 \pm 0.9$ & $2.2 \pm 1.3$ \\
& Normal testis & $2.5 \pm 1.1$ & $2.3 \pm 1.0$ \\
PPAR- $\gamma$ & Seminoma & $2.2 \pm 0.8^{\mathrm{a}}$ & $1.9 \pm 0.9^{\mathrm{a}}$ \\
& Embryonal carcinoma & $2.8 \pm 1.1^{\mathrm{a}}$ & $2.5 \pm 1.0^{\mathrm{a}}$ \\
& Yolk sac tumor & $2.2 \pm 0.9^{\mathrm{a}}$ & $2.1 \pm 1.1^{\mathrm{a}}$ \\
& Choriocarcinoma & $2.9 \pm 1.0^{\mathrm{a}}$ & $2.4 \pm 1.0^{\mathrm{a}}$ \\
& Teratoma & $2.0 \pm 1.3^{\mathrm{a}}$ & $1.9 \pm 1.1^{\mathrm{a}}$ \\
& Normal testis & $0.7 \pm 0.6$ & $0.6 \pm 0.4$ \\
\hline
\end{tabular}

Grading (0-4) was carried out on the coded sections by two observers in a blinded manner. 0 , no staining; 4 , maximum intensity. There were no significant differences in the intensity of PPAR- $\alpha,-\beta$ expression among any of the types of TC and NT tissues. However, PPAR- $\gamma$ expression was significantly more intense and extensive in all types of TC tissues as compared with NT tissues. ${ }^{\mathrm{a}} \mathrm{p}<0.001$. and examined the intensity of PPAR- $\alpha,-\beta$ and $-\gamma$ expression in the samples. There were no significant differences in the intensity of PPAR- $\alpha$ and $-\beta$ expression between any of the TC and NT tissues. However, PPAR- $\gamma$ expression was significantly more intense and extensive in the TC tissues than in the NT tissues (20) (Table II).

The PPAR- $\gamma$ ligands troglitazone and $15-\mathrm{d}-\mathrm{PGJ}_{2}$ induced the reduction of NEC- 8 viability in the range of $10-40 \mu \mathrm{M}$ as shown by the MTT assay (Table I). NEC- 8 cells treated with the PPAR- $\gamma$ ligand ( $25 \mu \mathrm{M}$ troglitazone and $\left.15-\mathrm{d}-\mathrm{PGJ}_{2}\right)$ entered early apoptosis, but not late apoptosis, necrosis or DNA fragmentation by flow cytometry (Fig. 3). Currently, no further data on TC and PPAR- $\gamma$ have been reported besides that of the present review. Thus, additional research is needed.

In conclusion, PPAR $-\gamma$ is strong in TC, and the anti-cancer effect of the PPAR- $\gamma$ ligand is significantly greater than that of the 5-LOX inhibitor. The anti-cancer effect of the PPAR- $\gamma$ ligand is relatively weak. Targeting PPAR- $\gamma$ in TC is likely to be useful more as a chemopreventive rather than a chemotherapeutic measure.

\section{Conclusion}

There is no question that COX-2, LOX (particularly 5-LOX) and PPAR $-\gamma$ are involved in the initiation and promotion of TC tissues. It may be possible to use COX-2 and 5-LOX inhibitor and PPAR- $\gamma$ ligand together as an anti-cancer drug for chemopreventive therapy in a single administration at a clinical dose. However this, in particular the combination of COX-2 and 5-LOX inhibitor, and even that of PPAR- $\gamma$ ligand, may prove difficult. However, the clinical application of 
A

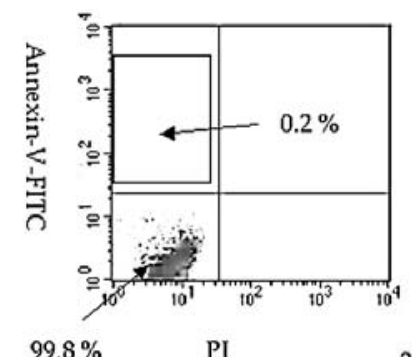

control

B

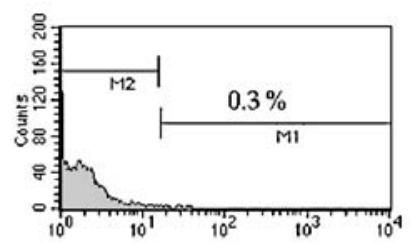

dUTP FITC

control

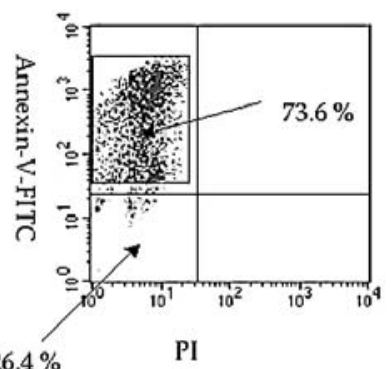

$25 \mu \mathrm{M}$ PPAR ligand $\left(15-\mathrm{d}-\mathrm{PG} \mathrm{J}_{2}\right)$

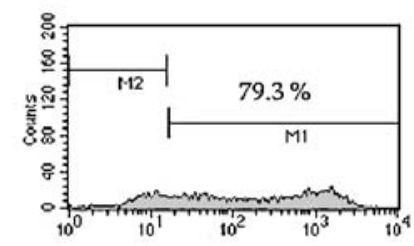

dUTP FITC

25 $\mu$ M PPAR ligand $\left(15-\mathrm{d}-\mathrm{PGJ} \mathrm{J}_{2}\right)$

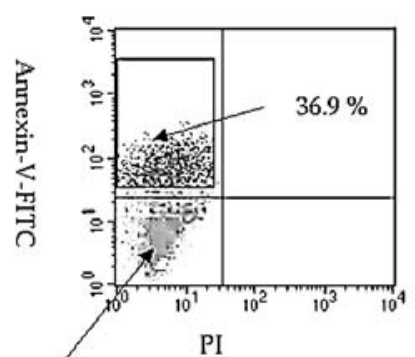

$63.1 \% \quad 25 \mu \mathrm{M}$ PPAR ligand

(Troglitazone)

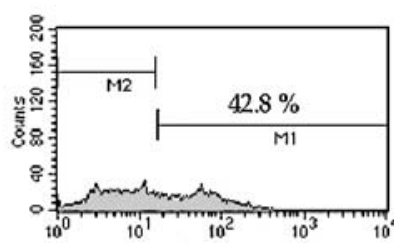

dUTP FITC

25 MMPPAR ligand

(Troglitazone)

Figure 3. Effects of the PPAR- $\gamma$ ligand on apoptosis by flow cytometry in the TC cell line NEC- 8 t. Treatment with $25 \mu \mathrm{M}$ PPAR- $\gamma$ ligands (troglitazone and 15-d-PGJ ${ }_{2}$ ) induced early apoptosis but not late apoptosis or necrosis in the TC cell line NEC-8. The top left quadrants represent early apoptosis. Diagrams of FITC-Annexin V/PI flow cytometry are presented (A). Treatment with $25 \mu \mathrm{M}$ PPAR- $\gamma$ ligands (troglitazone and $15-\mathrm{d}-\mathrm{PGJ}{ }_{2}$ ) induced DNA fragmentation in NEC-8. Typical flow cytometric analysis histograms are presented (B).

PPAR- $\gamma$ ligand and 5-LOX inhibitor requires further research and consideration, as the target of PPAR- $\gamma$ ligand and 5-LOX inhibitor is a novel strategy for human TC.

We conclude that the administration of COX-2 and 5-LOX inhibitors and PPAR $-\gamma$ ligand are beneficial with standard treatment in human TC. In the near future, the combination therapy of COX-2 and 5-LOX inhibitors and PPAR- $\gamma$ ligand will be a valuable new treatment for human TC.

\section{References}

1. Sano H, Kawahito Y, Wilder RL, et al: Expression of cyclooxygenase-1 and -2 in human colorectal cancer. Cancer Res 55: 3785-3789, 1995.

2. Yoshimura R, Matsuyama M, Tsuchida K, Kawahito Y, Sano H and Nakatani T: Expression of lipoxygenase in human bladder carcinoma and growth inhibition by its inhibitors. J Urol 170 1994-1999, 2003.

3. Xie W, Chipman JG, Robertson DL, Erikson RL and Simmons DL: Expression of a mitogen-responsive gene encoding prostaglandin synthase is regulated by mRNA splicing. Proc Natl Acad Sci USA 88: 2692-2696, 1991.

4. Sigal E: The molecular biology of mammalian arachidonic acid metabolism. Am J Physiol 260: 13-28, 1991.

5. Funk CD: The molecular biology of mammalian lipoxygenases and the quest for eicosanoid functions using lipoxygenasedeficient mice. Biochim Biophys Acta 1304: 65-84, 1996.

6. Matsuyama M, Hayama T, Funao K, et al: Overexpression of cysteinylLT1 receptor in prostate cancer and CysLT1R antagonist inhibits prostate cancer cell growth through apoptosis. Oncol Rep 18: 99-104, 2007.

7. Issemann I and Green S: Activation of a member of the steroid hormone receptor superfamily by peroxisome proliferator. Nature 347: 645-650, 1990.

8. Braissant O, Foufelle F, Scotto C, Dauca M and Wahli W: Differential expression of peroxisome proliferator-activated receptors (PPARs). Tissue distribution of PPAR-alpha, -beta, and -gamma in the adult rat. Endocrinology 137: 354-366, 1996.
9. Mukherjee R, Jow L, Croston GE and Paterniti JR Jr: Identification, characterization, and tissue distribution of human peroxisome proliferator-activated receptor (PPAR) isoforms PPARgamma2 versus PPARgamma1 and activation with retinoid X receptor agonists and antagonists. J Biol Chem 272: 8071-8076, 1997.

10. Kawahito Y, Kondo M, Tsubouchi Y, et al: 15-deoxy-delta(12,14)PGJ(2) induces synoviocyte apoptosis and suppresses adjuvantinduced arthritis in rats. J Clin Invest 106: 189-197, 2000.

11. Tsubouchi Y, Sano H, Kawahito Y, et al: Inhibition of human lung cancer cell growth by the peroxisome proliferator-activated receptor- $\gamma$ agonists through induction of apoptosis. Biochem Biophys Res Commun 270: 400-405, 2000.

12. Inoue K, Kawahito Y, Tsubouchi Y, Kohno M, Yoshimura R, Yoshikawa T and Sano H: Expression of peroxisome proliferatoractivated receptor gamma in renal cell carcinoma and growth inhibition by its agonists. Biochem Biophys Res Commun 287: 727-732, 2001.

13. Hase T, Yoshimura R, Matsuyama M, et al: Cyclooxygenase-1 and -2 in human testicular tumours. Eur J Cancer 39: 2043-2049, 2003.

14. Yoshimura R, Matsuyama M, Kawahito Y, et al: Study of cyclooxygenase-2 in renal cell carcinoma. Int J Mol Med 13: 229-233, 2004.

15. Yoshimura R, Sano H, Mitsuhashi M, Kohno M, Chargui J and Wada S: Expression of cyclooxygenase-2 in patients with bladder carcinoma. J Urol 165: 1468-1472, 2001.

16. Yoshimura R, Sano H, Masuda C, et al: Expression of cyclooxygenase-2 in prostate carcinoma. Cancer 89: 589-596, 2000.

17. Hwang D, Scollard D, Byrne J and Levine E: Expression of cyclooxygenase- 1 and cyclooxygenase- 2 in human breast cancer. J Natl Cancer Inst 90: 455-460, 1998.

18. Yoshimura R, Matsuyama M, Mitsuhashi M, et al: Relationship between lipoxygenase and human testicular cancer. Int J Mol Med 13: 389-393, 2004.

19. Goto HG, Nishizawa Y, Katayama H, et al: Induction of apoptosis in an estrogen-responsive mouse Leydig tumor cell by leukotriene. Oncol Rep 17: 225-232, 2007.

20. Hase T, Yoshimura R, Mitsuhashi M, et al: Expression of peroxisome proliferator-activated receptors in human testicular cancer and growth inhibition by its agonists. Urology 60: 542-547, 2002. 